\title{
Brucella pneumonia with microabscess and pleural effusion
}

\author{
Recep Tekin ${ }^{[1]}$
}

[1]. Department of Infectious Disease and Clinical Microbiology, Dicle University School of Medicine, Diyarbakir, Turkey.

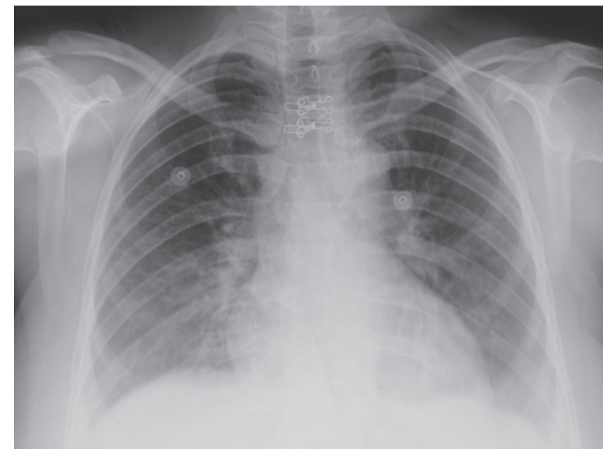

(A)

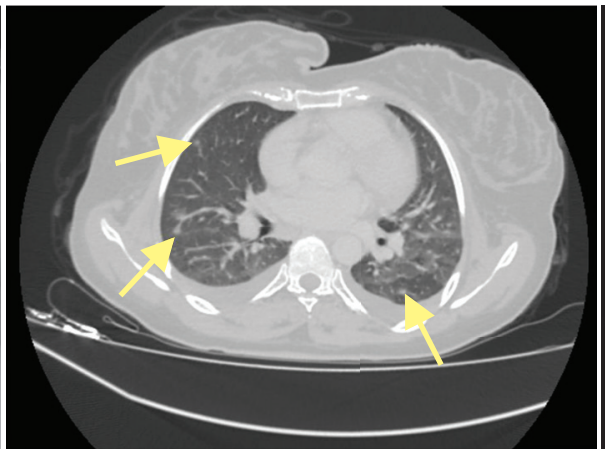

(B)



(C)
A 36-year-old woman was admitted to the hospital with a one-month history of fever, night sweats, and anorexia. A week before admission, she developed cough, hemoptysis, and pleuritic pain in both lungs. Her history revealed raw milk ingestion and contact with animals. Physical examination showed signs of pleural effusion in both lungs and hepatosplenomegaly. The laboratory test results were as follows: white blood cell count, $2,900 \mathrm{~mm}^{3}$; platelets, $65 / \mathrm{mm}^{3}$; hemoglobin, 9.1g/dL; C-reactive protein, $7.6 \mathrm{mg} / \mathrm{dL}$ (normal range, $0-0.8 \mathrm{mg} / \mathrm{dL}$ ); aspartate aminotransferase, $223 \mathrm{IU} / \mathrm{L}$; alanine aminotransferase, 55IU/L; and total bilirubin, $4 \mathrm{mg} / \mathrm{dL}$. Brucella agglutinin antibodies were positive for Brucella abortus with a titer of $1 / 640$. Chest radiography showed paratracheal lymphadenopathy and pleural effusion in both lungs (Figure A). Computed tomographic scan of the chest showed mm-sized subpleural microabscesses (Figure B, yellow arrow), multiple mediastinal lymph nodes with the largest being $16 \times 12 \mathrm{~mm}$ in size (Figure $\mathbf{C}$, green curved arrow), and pleural effusion in both lungs (Figure $\mathbf{C}$, yellow arrow). The patient was treated perorally with doxycycline, $200 \mathrm{mg} /$ day; rifampicin, 600mg/day; and imipenem, 2,000mg/day. The blood cultures grew Brucella species. Her fever subsided after eight days, and she continued to take oral doxycycline and rifampicin at the same doses for six weeks. She was followed up in the outpatient clinic for three months. Pleural effusion was absent and hepatosplenomegaly had regressed. Although involvement of the respiratory system in brucellosis has been acknowledged, it is a rare occurrence and its non-specific findings and focal complications often make diagnosis difficult.

\section{REFERENCES}

1. Erdem H, Inan A, Elaldi N, Tekin R, Gulsun S, Ataman-Hatipoglu $\mathrm{C}$, et al. Respiratory system involvement in brucellosis: the results of the Kardelen study. Chest 2014; 145:87-94.

2. Günal O, Berk S, Barut HS. Pulmonary involvement in brucellosis. J Exp Clin Med 2011; 28:128-131.

3. Al-Anazi AR, Aziz S, Fouda MA. Brucellosis: haemorrhagic pleural effusion. Med Princ Pract 2005; 14:118-120.

Corresponding author: Dr. Recep Tekin. Department of Infectious Disease and Clinical Microbiology, Dicle University School of Medicine, Yenişehir 21280 Diyarbakır, Turkey.

Phone: 9041224880 01-4775; Fax: 90412 248-8440

e-mail: rectek21@hotmail.com

Received 6 January 2015

Accepted 2 February 2015 